\title{
PANORAMA DA DIVERSIDADE PRODUTIVA \\ E DE RENDA NA AGROPECUÁRIA \\ BRASILEIRA: UMA BREVE INCURSÃO \\ NOS DADOS DO CENSO DE 2017
}

Gesmar Rosa dos Santos²
Adrielli Santos de Santana

\section{INTRODUÇÃO}

Nas últimas três décadas, nenhuma das maiores agriculturas do planeta passou por transformaçóes produtivas, mudanças nos usos da terra e alcance de mercados externos táo intensos quanto a brasileira. O país alcançou volume de produção capaz de garantir a sua segurança alimentar, com crescentes superavit na balança comercial, fruto da incorporaçáo de tecnologias e da expansão da fronteira agrícola, além de ter mantido também importantes políticas inclusivas no meio rural, ainda que insuficientes. Ao mesmo tempo, observa-se uma realidade não menos significativa de diversidade produtiva e de renda que se mantém com muitas dificuldades e desafios, sejam de natureza regional ou de escala, como se verá neste e nos demais textos deste boletim.

Para compreender o que se passou nesse período é importante ter em conta os sobressaltos da trajetória da agropecuária e complexos agroindustriais do país (Ramos, 2007; Belik, 2007), assim como as mudanças nos mercados e o papel das políticas públicas no combate às heterogeneidades e às desigualdades (Belik, 2015). Ao mesmo tempo, observar os dados do presente permite que sejam levantadas perguntas e hipóteses acerca dos efeitos mais impactantes das políticas. Nesse sentido, este ensaio descreve os resultados do Censo Agropecuário de 2017 a partir de recortes e variáveis selecionadas de modo a exemplificar a diversidade da agropecuária no Brasil. Segue-se no texto a discussão apresentada por Santos, Vian e Mattei (2020), ensaio que abre este boletim, com recorte na agricultura familiar.

O objetivo central deste ensaio é destacar elementos da diversidade produtiva, de renda e de ativos nos estabelecimentos segundo dados do Censo Agropecuário de 2017, de modo a introduzir temas e questôes sobre as quais alguns textos deste boletim vão abordar. Mesmo

1. DOI: http://dx.doi.org/10.38116/brua23art4

2. Técnico de planejamento e pesquisa na Diretoria de Estudos e Políticas Regionais, Urbanas e Ambientais (Dirur) do Ipea. 3. Pesquisadora do Programa de Pesquisa para o Desenvolvimento Nacional (PNPD) na Dirur/lpea; e doutoranda em economia na Universidade de Brasília (UnB). 
considerando que as trajetórias, os aprendizados e as teorias são as principais chaves para se discutir o tema da diversidade, optamos por iniciar com a análise descritiva dos dados, seguindo o propósito geral de levantar questôes sobre o aperfeiçoamento das políticas agropecuárias.

Para seguir esse caminho, foram selecionadas variáveis-chave a respeito da situaçáo de acesso aos ativos, limitaçóes estruturais e produtivas que ajudam a caracterizar a heterogeneidade da agropecuária com recorte no agricultor familiar em algumas variáveis. Esse segmento de produtores tem motivado um grande número de iniciativas do governo federal, desde meados dos anos 1990, as quais se materializam no orçamento da política agrícola nacional (Santos e Freitas, 2017) e em açóes de desenvolvimento rural do país (Schneider, 2010; Schneider et al., 2013; Silva, 2015; Lima et al., 2019).

O enfoque regional é oportuno, adicionalmente, devido às diferenças entre os biomas e as condiçóes de produção em cada categoria de produtores (Baiardi e Alencar, 2014), bem como por tornar mais perceptível a complexidade de realidades. Embora mudanças metodológicas introduzidas pelo Instituto Brasileiro de Geografia e Estatística (IBGE) limitem comparaçóes de algumas variáveis e estabelecimentos com os recenseamentos anteriores (Del Grossi, 2019), os distintos contextos da produção agropecuária, por regiōes, municípios e categorias de estabelecimentos, podem ser obtidos. Dessa forma, evidenciam-se dados das heterogeneidades estrutural (HE), ${ }_{4}^{4}$ produtiva $(\mathrm{HP})^{5}$ e de renda dos estabelecimentos, de modo agregado por Unidades da Federação (UFs).

A hipótese levantada é que as heterogeneidades e as diversidades se manifestam distinta e regionalmente nos estratos de porte de estabelecimentos e nas categorias familiar e não familiar. Considerando-se também a possibilidade de esvaziamento do ciclo atual das políticas para a agricultura e para o desenvolvimento rural, como ilustrado em Lima et al. (2019), destacam-se dados que permitirão discutir, futuramente, aspectos centrais para um possível novo ciclo ou para o aperfeiçoamento dessas políticas.

$\mathrm{O}$ artigo contém três seções, além desta introdução. $\mathrm{Na}$ seção 2 apresentam-se os dados característicos da estrutura dos estabelecimentos e variáveis derivadas relativas à produtividade e ao rendimento médio agropecuário. Na seção 3 são destacados os aspectos sociais, de acesso aos ativos e de organização produtiva por UFs e por regiōes. Por fim, na seção 4 encontram-se algumas conclusões acerca do breve diagnóstico realizado.

\section{DADOS ESTRUTURAIS E PRODUTIVOS DOS ESTABELECIMENTOS}

Um ponto de partida para a análise dos dados que retratam o ambiente rural e a produção agrícola é o conjunto de variáveis sociais, agrárias e de potencial econômico regional, além das produtivas e tecnológicas. Optou-se por utilizar variáveis que expressem as HEs e HPs (variáveis sobre área total, porte, recorte regional/UF e rendimento por área). Acesso à terra $\mathrm{e}$ água para irrigação, extensão rural, tecnologias, obtenção de renda externa e outras são também importantes referenciais para estudos da HE e HP (Vieira Filho, Santos e Fornazier, 2013)

\footnotetext{
4. Adota-se neste texto a definição de HE como a manifestação de disparidades estáticas, que não dependem apenas da melhor alocação de fatores em um mercado de livre concorrência, e HP como "a persistência de profundas diferenças dos resultados da atividade econômica dos estabelecimentos (nível de produção, valor adicionado e renda líquida)", conforme Vieira Filho, Santos e Fornazier (2013, p. 10) e Santos, Vian e Mattei (2020).

5. Para informações sobre a HP na visão da Comissão das Nações Unidas para a América Latina e o Caribe (Cepal), ver, neste boletim, o texto de Murilo José de Souza Pires, para quem a HP é um hiato entre os estabelecimentos agrícolas modernos e atrasados, medida pela produtividade do trabalho.
} 
e, ao mesmo tempo, sinais de pluriatividade e de multifuncionalidade dos estabelecimentos (Schneider et al., 2013), compondo a diversidade agrária e produtiva.

A tabela 1 apresenta algumas dessas variáveis, destacando o grande porte da agricultura brasileira (Valor Bruto da Produção - VBP de R \$ 465 bilhóes) e o grande contingente ocupado no campo (acima de 15 milhóes mantido por trinta anos). Foram 74,83\% dos estabelecimentos com renda da produção agrícola, em 2017, sendo que a região Nordeste tem a maior parte dos estabelecimentos sem renda da produçáo agropecuária, principalmente no Semiárido (64,1\% com produçáo), embora o seu VBP tenha se aproximado de R \$ 30 bilhôes, ilustrando a importância regional da agricultura.

TABELA 1

Características produtivas dos estabelecimentos agropecuários por UF

\begin{tabular}{|c|c|c|c|c|c|}
\hline Unidade territorial & $\begin{array}{c}\text { Total de } \\
\text { ocupados no } \\
\text { estabelecimento (unidades) }\end{array}$ & $\begin{array}{c}\text { Estabelecimentos com } \\
\text { renda da produção } \\
\text { agrícola }(\%)\end{array}$ & $\begin{array}{c}\text { VBP } \\
\text { (R\$ mil) }\end{array}$ & $\begin{array}{l}\text { Participação das } \\
\text { UFs no VBP } \\
\text { total (\%) }\end{array}$ & $\begin{array}{c}\text { Participação das UFs } \\
\text { na receita total } \\
\text { da produção (\%) }\end{array}$ \\
\hline Brasil & 15.105 .125 & 74,83 & 465.105 .945 & 100,00 & 100,00 \\
\hline Rondônia & 270.812 & 84,31 & 6.544 .964 & 1,41 & 1,56 \\
\hline Acre & 126.514 & 82,03 & 1.216 .731 & 0,26 & 0,24 \\
\hline Amazonas & 330.719 & 87,39 & 1.932 .083 & 0,42 & 0,36 \\
\hline Roraima & 67.070 & 68,90 & 758.861 & 0,16 & 0,15 \\
\hline Pará & 979.648 & 86,28 & 13.541 .906 & 2,91 & 2,99 \\
\hline Amapá & 31.098 & 89,82 & 352.746 & 0,08 & 0,07 \\
\hline Tocantins & 204.430 & 82,45 & 6.712 .464 & 1,44 & 1,59 \\
\hline Maranhão & 692.870 & 71,31 & 7.238 .741 & 1,56 & 1,56 \\
\hline Piauí & 670.321 & 60,35 & 4.809 .495 & 1,03 & 0,94 \\
\hline Ceará & 928.646 & 59,95 & 5.548 .695 & 1,19 & 1,05 \\
\hline Rio Grande do Norte & 213.883 & 80,28 & 2.498 .913 & 0,54 & 0,55 \\
\hline Paraíba & 424.116 & 66,57 & 2.250 .664 & 0,48 & 0,49 \\
\hline Pernambuco & 779.727 & 60,10 & 5.645 .644 & 1,21 & 1,23 \\
\hline Alagoas & 326.913 & 63,61 & 2.567 .419 & 0,55 & 0,50 \\
\hline Sergipe & 234.161 & 77,78 & 1.950 .361 & 0,42 & 0,45 \\
\hline Bahia & 2.106 .127 & 72,46 & 21.043 .026 & 4,52 & 4,62 \\
\hline Minas Gerais & 1.836 .353 & 74,41 & 59.841 .258 & 12,87 & 12,57 \\
\hline Espírito Santo & 357.258 & 84,59 & 7.614 .992 & 1,64 & 1,68 \\
\hline Rio de Janeiro & 160.571 & 81,47 & 2.982 .758 & 0,64 & 0,69 \\
\hline São Paulo & 833.195 & 78,57 & 61.592 .192 & 13,24 & 12,09 \\
\hline Paraná & 846.642 & 83,15 & 48.585 .382 & 10,45 & 10,26 \\
\hline Santa Catarina & 501.811 & 83,16 & 20.483 .087 & 4,40 & 4,20 \\
\hline Rio Grande do Sul & 992.413 & 86,62 & 54.250 .540 & 11,66 & 11,52 \\
\hline Mato Grosso do Sul & 254.971 & 77,76 & 26.874 .584 & 5,78 & 6,15 \\
\hline Mato Grosso & 422.453 & 77,63 & 58.643 .756 & 12,61 & 13,53 \\
\hline Goiás & 490.612 & 82,58 & 38.584 .612 & 8,30 & 8,73 \\
\hline Distrito Federal & 21.791 & 92,22 & 1.040 .071 & 0,22 & 0,24 \\
\hline
\end{tabular}

Fonte: IBGE (2020)

Elaboração dos autores.

Outro destaque da tabela 1 é a participação das UFs no VBP total. O fato de sete estados do Centro-Sul do país (São Paulo, Minas Gerais, Mato Grosso, Goiás, Mato Grosso do Sul, Paraná e Rio Grande do Sul) concentrarem 75\% da produção agropecuária, havendo onze 
UFs com menos de $1 \%$, sendo que isso se repete no caso da receita de vendas, sugere que: i) de fato, faz sentido que a política agrícola tenha o âmbito nacional (para alcançar a todos que dela dependem ${ }^{6}$ com regras gerais), com recortes regionais (para considerar as funçóes sociais, econômicas, estruturais e ambientais); e ii) a capilaridade regional possibilita mercados não homogêneos, de modo que são viabilizadas cadeias produtivas com características locais próprias, paralelamente a sistemas produtivos integrados/homogêneos. Nesse cenário é compreensível a existência de sistemas de produçáo e produtores com distintas produtividades e HP. Dessa forma, além das políticas federais, cabe a atuação dos estados, do Distrito Federal e mesmo de municípios no fomento e fortalecimento do potencial dos produtos e cadeias de valor locais. É também importante estudar como esses e outros componentes da produtividade total dos fatores na agropecuária se relacionam com a segurança alimentar regional e local.

Variáveis derivadas e índices básicos da produção são também importantes para análises, por serem capazes de indicar pontos que necessitam de aprofundamento de estudos, somando-se o conjunto de fatores estruturais e ambientais. Por exemplo, a tabela 2 apresenta dados de produtividade do trabalho (medida pelo VBP/população total ocupada - $\mathrm{PTO})^{7} \mathrm{e}$ rendimento monetário médio por área colhida, trazidos pelas declaraçóes do censo de 2017.

TABELA 2

Referencial de porte, produtividade dos estabelecimentos com receita da produção e rendimento médio por área total (2017)

\begin{tabular}{|c|c|c|c|c|}
\hline UF & $\begin{array}{l}\text { Referencial de porte } \\
\text { dos estabelecimentos } \\
\text { nas UFs (R\$ mil/ } \\
\text { estabelecimento) }\end{array}$ & $\begin{array}{l}\text { Produtividade média } \\
\text { do trabalho (R\$ mil/ } \\
\text { pessoal ocupado) }\end{array}$ & $\begin{array}{c}\text { Receita média por porte } \\
\text { (receita de vendas/área } \\
\text { total dos estabelecimentos) } \\
\text { (R\$ mil/ha) }\end{array}$ & $\begin{array}{c}\text { Rendimento monetário } \\
\text { médio por área colhida } \\
\text { na lavoura temporária } \\
\text { (R\$ mil/ha) }\end{array}$ \\
\hline Brasil & 107,13 & 30,79 & 1,18 & 3,50 \\
\hline Rondônia & 82,58 & 24,17 & 0,70 & 2,77 \\
\hline Acre & 32,32 & 9,62 & 0,24 & 7,49 \\
\hline Amazonas & 20,70 & 5,84 & 0,37 & 10,42 \\
\hline Roraima & 53,66 & 11,31 & 0,24 & 4,38 \\
\hline Pará & 50,44 & 13,82 & 0,44 & 4,73 \\
\hline Amapá & 40,11 & 11,34 & 0,20 & 5,51 \\
\hline Tocantins & 123,37 & 32,84 & 0,43 & 2,92 \\
\hline Maranhão & 40,70 & 10,45 & 0,53 & 2,86 \\
\hline Piauí & 25,45 & 7,17 & 0,39 & 2,57 \\
\hline Ceará & 17,47 & 5,98 & 0,63 & 0,95 \\
\hline Rio Grande do Norte & 44,12 & 11,68 & 0,83 & 3,95 \\
\hline Paraíba & 18,38 & 5,31 & 0,59 & 2,32 \\
\hline Pernambuco & 29,42 & 7,24 & 1,14 & 2,75 \\
\hline Alagoas & 31,97 & 7,85 & 1,25 & 3,68 \\
\hline Sergipe & 25,55 & 8,33 & 1,29 & 2,54 \\
\hline Bahia & 33,99 & 9,99 & 0,68 & 3,53 \\
\hline
\end{tabular}

6. Há no Brasil estimativas de que o crédito público controlado (com recursos orçamentários) atende a um terço da necessidade da cadeia agropecuária, sendo os demais disponibilizados por bancos, indústrias e empresas comercializadoras de commodities (Santos e Freitas, 2017; Freitas e Santos, 2017).

7. A produtividade do trabalho obtida pelo total de horas trabalhadas é mais precisa que pela PTO (Barbosa Filho e Pessôa, 2014), assim como o valor adicionado em lugar do VBP. No caso da agricultura, isso se ressalta devido à pluriatividade e à sazonalidade. 0 censo, porém, não traz horas trabalhadas. 


\begin{tabular}{|c|c|c|c|c|}
\hline UF & $\begin{array}{l}\text { Referencial de porte } \\
\text { dos estabelecimentos } \\
\text { nas UFs (R\$ mil/ } \\
\text { estabelecimento) }\end{array}$ & $\begin{array}{l}\text { Produtividade média } \\
\text { do trabalho (R\$ mil/ } \\
\text { pessoal ocupado) }\end{array}$ & $\begin{array}{c}\text { Receita média por porte } \\
\text { (receita de vendas/área } \\
\text { total dos estabelecimentos) } \\
\text { (R\$ mil/ha) }\end{array}$ & $\begin{array}{c}\text { Rendimento monetário } \\
\text { médio por área colhida } \\
\text { na lavoura temporária } \\
\text { (R\$ mil/ha) }\end{array}$ \\
\hline Minas Gerais & 113,47 & 32,59 & 1,36 & 4,32 \\
\hline Espírito Santo & 75,25 & 21,32 & 2,14 & 4,23 \\
\hline Rio de Janeiro & 53,29 & 18,58 & 1,20 & 7,12 \\
\hline São Paulo & 333,57 & 73,92 & 3,03 & 4,69 \\
\hline Paraná & 164,85 & 57,39 & 2,88 & 3,28 \\
\hline Santa Catarina & 112,49 & 40,82 & 2,70 & 4,82 \\
\hline Rio Grande do Sul & 149,06 & 54,67 & 2,20 & 3,79 \\
\hline Mato Grosso do Sul & 452,58 & 105,40 & 0,83 & 3,02 \\
\hline Mato Grosso & 594,16 & 138,82 & 1,02 & 2,92 \\
\hline Goiás & 283,93 & 78,65 & 1,38 & 3,63 \\
\hline Distrito Federal & 200,55 & 47,73 & 3,81 & 3,25 \\
\hline Coeficiente de variação & 120,61 & 107,65 & 80,68 & 47,08 \\
\hline
\end{tabular}

Como se observa na tabela 2, há disparidades de valores em todas as variáveis selecionadas, a começar pela esperada alta produtividade do trabalho no Centro-Oeste - em razáo de mecanizaçáo em grandes áreas, existência de duas safras, tecnologia de ponta, entre outros fatores distintos de demais regiôes. Os coeficientes de variação apontam grande heterogeneidade nas quatro variáveis. Os dados dos estados do Amazonas, Acre, Amapá e Rio de Janeiro devem ser analisados com maior profundidade, haja vista os inesperados altos rendimentos monetários por área colhida nas lavouras temporárias - podendo haver inconsistência das respostas, ou cultivos de alto rendimento em condições específicas. Há de se estudar, além da grande heterogeneidade por UF, as razóes de esse rendimento, por exemplo, no Sul do país (que alia commodities e pequena produção), superar o do Centro-Oeste (tipicamente commodities), embora com menor produtividade do trabalho. Apesar de ser conhecido o fato de cultivos como frutas, flores e hortaliças náo demandarem grande quantidade de terra, importa investigar como, onde e em que condiçôes e produtos ambos os resultados contam com políticas públicas.

\section{CARACTERÍSTICAS SOCIAIS E ACESSO A ATIVOS PRODUTIVOS}

Um conjunto de variáveis socioeconômicas do censo de 2017 possibilita delinear o perfil dos produtores, além de evidenciar as categorias estabelecidas pela Lei ํㅜㄹ 11.326/2006, regulamentada pelo Decreto oㅜ 9.064/2017 como familiares, que são, resumidamente, aquelas com tamanho de até quatro módulos fiscais; residem e dirigem o próprio estabelecimento; têm pelo menos metade da máo de obra predominantemente familiar; e pelo menos metade da renda anual oriunda da produção do estabelecimento. ${ }^{8}$ Os estabelecimentos não enquadrados nessas características são denominados não familiares para os efeitos da lei.

A tabela 3 ilustra, para todas as regiôes e UFs, algumas das variáveis mencionadas, evidenciando o predomínio dos estabelecimentos familiares, principalmente nas regiôes

8. Seguindo a Lei no 11.326/2006, a Portaria no 234/2017 e a Portaria no 001/2017 detalham as condições e os procedimentos para a emissão da Declaração de Aptidão ao Pronaf (DAP), a Unidade Familiar de Produção Rural (UFPR) e aspectos como as condições de acesso ao Programa Nacional de Fortalecimento da Agricultura Familiar (Pronaf) (renda até R\$360 mil) e cooperativas. 
Nordeste, Norte e Sul. Em todo o país, eles são 76,8\% dos estabelecimentos, e em dez estados somam mais de $80 \%$. Entretanto, como se destaca em outros textos deste boletim, apesar de sua grande importância, essa categoria, entre outras privaçóes, detém apenas 23\% das terras.

TABELA 3

Características sociais da população total e dos estabelecimentos por UF: variáveis selecionadas (2017)

\begin{tabular}{|c|c|c|c|c|c|c|}
\hline Regiões & UF & $\begin{array}{l}\text { Mulheres na } \\
\text { direção (\%) }\end{array}$ & $\begin{array}{l}\text { Idade (até } \\
35 \text { anos) }\end{array}$ & $\begin{array}{l}\text { Escolaridade (até 10 grau } \\
\text { completo, inclui EJA) (\%) }\end{array}$ & $\begin{array}{l}\text { Escolaridade (até } 2 \text { o grau } \\
\text { completo, inclui EJA) }(\%)\end{array}$ & $\begin{array}{c}\text { Estabelecimentos da } \\
\text { agricultura familiar (\%) }\end{array}$ \\
\hline \multirow{7}{*}{ Norte } & RO & 15,7 & 13,1 & 18,4 & 14,3 & 81,3 \\
\hline & $A C$ & 20,2 & 21,8 & 22,4 & 14,2 & 83,3 \\
\hline & AM & 20,9 & 21,5 & 28,5 & 15,5 & 86,9 \\
\hline & $\mathrm{RR}$ & 21,7 & 17,9 & 25,6 & 19,0 & 77,8 \\
\hline & PA & 20,4 & 17,9 & 34,4 & 11,5 & 85,1 \\
\hline & $A P$ & 23,3 & 19,8 & 32,2 & 18,1 & 82,1 \\
\hline & TO & 16,2 & 8,2 & 17,3 & 17,5 & 70,5 \\
\hline \multirow{9}{*}{ Nordeste } & MA & 20,4 & 15,7 & 20,1 & 10,0 & 85,1 \\
\hline & PI & 22,1 & 14,2 & 17,6 & 8,3 & 80,3 \\
\hline & CE & 19,3 & 13,4 & 24,6 & 9,8 & 75,5 \\
\hline & RN & 15,8 & 9,8 & 18,1 & 12,2 & 79,9 \\
\hline & PB & 23,1 & 11,7 & 17,8 & 8,7 & 76,9 \\
\hline & PE & 27,1 & 14,4 & 19,3 & 11,0 & 82,6 \\
\hline & $\mathrm{AL}$ & 23,3 & 14,5 & 19,2 & 8,9 & 83,6 \\
\hline & SE & 22,6 & 11,4 & 22,7 & 10,8 & 77,3 \\
\hline & BA & 25,5 & 11,2 & 15,9 & 11,9 & 77,8 \\
\hline \multirow{4}{*}{ Centro-Oeste } & MS & 19,2 & 8,1 & 14,3 & 17,5 & 60,7 \\
\hline & MT & 16,8 & 9,0 & 14,6 & 19,2 & 68,8 \\
\hline & GO & 14,7 & 5,4 & 14,1 & 19,2 & 62,9 \\
\hline & DF & 16,1 & 9,3 & 21,9 & 21,0 & 52,1 \\
\hline \multirow{4}{*}{ Sudeste } & MG & 14,3 & 7,6 & 17,6 & 13,1 & 72,7 \\
\hline & ES & 13,6 & 11,3 & 21,9 & 14,9 & 74,8 \\
\hline & RJ & 15,7 & 8,5 & 22,2 & 15,5 & 67,1 \\
\hline & $S P$ & 12,7 & 6,0 & 12,1 & 19,1 & 65,0 \\
\hline \multirow{3}{*}{ Sul } & $P R$ & 13,3 & 9,2 & 10,7 & 18,2 & 75,0 \\
\hline & SC & 10,3 & 8,5 & 13,3 & 14,6 & 78,1 \\
\hline & RS & 12,0 & 7,9 & 30,7 & 11,9 & 80,5 \\
\hline \multicolumn{2}{|l|}{ Brasil } & 18,6 & 11,2 & 19,5 & 12,9 & 76,8 \\
\hline \multicolumn{7}{|c|}{$\begin{array}{l}\text { Elaboração dos autores. } \\
\text { Obs.: EJA - Educação de Jovens e Adultos; RO - Rondônia; AC- Acre; AM - Amazonas; RR - Roraima; PA - Pará; AP - Amapá; TO - Tocantins; } \\
\text { MA - Maranhão; PI - Piaúi; CE - Ceará; RN - Rio Grande do Norte; PB - Paraíba; PE - Pernambuco; AL - Alagoas; SE - Sergipe; BA - Bahia } \\
\text { MS - Mato Grosso do Sul; MT - Mato Grosso; GO - Goiás; DF - Distrito Federal; MG - Minas Gerais; ES - Espírito Santo; RJ - Rio de Janeiro; } \\
\text { SP - São Paulo; PR - Paraná; SC - Santa Catarina; RS - Rio Grande do Sul. }\end{array}$} \\
\hline
\end{tabular}

Cabe destacar também (tabela 3) que o comando feminino nos estabelecimentos, com média de 18,6\%, no Brasil se destaca no Norte e Nordeste, onde há estados com até $23 \%$ de mulheres no comando. Por sua vez, esse percentual fica abaixo de 15\% no Sul e Sudeste. Já o percentual de agricultores com idade até 35 anos é muito baixo, exceto na região Norte, sinalizando desafios à substituição intergeracional no campo. A baixa escolaridade dos agricultores pode estar ligada a esse fato, uma vez que a busca de oportunidades de estudos leva à saída de jovens do campo. Cabe um aprofundamento de estudos, nesses aspectos, 
principalmente nos estados da região Sul, São Paulo, Mato Grosso do Sul, Goiás, Tocantins e Minas Gerais.

Outro conjunto de variáveis ligadas às diversidades produtiva, estrutural e do ambiente rural destaca diferenças regionais e entre as UFs (tabela 4). Diversas políticas fortalecidas a partir da década de 1990, principalmente, objetivam ampliar acesso à energia, água para irrigaçáo, preparo do solo, uso de agrotóxicos (defensivos agrícolas), crédito, além de iniciativas dos produtores no tocante ao associativismo e ao cooperativismo, fatores que fortalecem o aumento da produção e da renda. Contudo, as disparidades são claras, como se observa na tabela.

TABELA 4

Variáveis de acesso a serviços, ativos físicos e de conhecimento, cooperativismo e uso de técnicas selecionadas (2017)

(Em \%)

\begin{tabular}{|c|c|c|c|c|c|c|c|c|}
\hline Regiões & UF & $\begin{array}{c}\text { Acesso à } \\
\text { energia elétrica }\end{array}$ & $\begin{array}{c}\text { Acesso a programas } \\
\text { de crédito }\end{array}$ & $\begin{array}{c}\text { Acesso à } \\
\text { orientação técnica }\end{array}$ & $\begin{array}{c}\text { Associação em } \\
\text { cooperativas }\end{array}$ & $\begin{array}{l}\text { Uso de } \\
\text { irrigação }\end{array}$ & $\begin{array}{l}\text { Preparo } \\
\text { do solo }\end{array}$ & $\begin{array}{l}\text { Uso de } \\
\text { agrotóxico }\end{array}$ \\
\hline \multirow{7}{*}{ Norte } & RO & 91,8 & 7,3 & 18,7 & 12,8 & 9,3 & 25,6 & 51,6 \\
\hline & $A C$ & 69,7 & 3,6 & 11,4 & 18,1 & 3,0 & 27,5 & 20,3 \\
\hline & AM & 52,5 & 1,7 & 12,0 & 8,8 & 7,1 & 20,8 & 11,5 \\
\hline & $\mathrm{RR}$ & 67,2 & 2,7 & 13,2 & 4,9 & 11,9 & 33,9 & 14,4 \\
\hline & PA & 68,3 & 2,3 & 6,0 & 17,2 & 5,1 & 30,6 & 15,6 \\
\hline & $A P$ & 65,6 & 2,0 & 15,2 & 6,9 & 16,7 & 48,5 & 12,2 \\
\hline & TO & 86,4 & 5,0 & 13,9 & 3,7 & 3,6 & 51,5 & 23,7 \\
\hline \multirow{9}{*}{ Nordeste } & MA & 60,8 & 3,1 & 4,2 & 32,0 & 3,2 & 29,7 & 25,4 \\
\hline & PI & 81,0 & 6,1 & 3,5 & 41,4 & 6,1 & 52,2 & 19,3 \\
\hline & $C E$ & 85,3 & 5,4 & 10,8 & 27,6 & 7,5 & 54,8 & 32,7 \\
\hline & RN & 90,2 & 9,3 & 16,1 & 30,3 & 15,0 & 79,8 & 34,7 \\
\hline & PB & 89,7 & 7,6 & 17,3 & 32,4 & 11,8 & 66,3 & 32,0 \\
\hline & $P E$ & 87,7 & 4,5 & 6,7 & 16,6 & 14,0 & 65,5 & 22,3 \\
\hline & $\mathrm{AL}$ & 80,3 & 4,7 & 6,2 & 8,9 & 6,3 & 69,9 & 30,9 \\
\hline & SE & 74,4 & 5,2 & 8,9 & 10,7 & 9,1 & 62,8 & 28,7 \\
\hline & BA & 74,1 & 5,0 & 7,7 & 18,8 & 12,3 & 57,2 & 16,5 \\
\hline \multirow{4}{*}{ Centro-Oeste } & MS & 92,2 & 6,9 & 31,8 & 8,0 & 3,6 & 48,7 & 21,9 \\
\hline & MT & 89,4 & 6,3 & 18,5 & 13,1 & 4,0 & 38,3 & 40,5 \\
\hline & $\mathrm{GO}$ & 91,9 & 6,3 & 22,0 & 8,6 & 5,4 & 38,7 & 24,2 \\
\hline & DF & 98,4 & 5,4 & 76,9 & 3,8 & 52,0 & 80,6 & 43,6 \\
\hline \multirow{4}{*}{ Sudeste } & MG & 90,6 & 9,7 & 26,2 & 20,8 & 10,6 & 50,5 & 27,4 \\
\hline & ES & 92,8 & 7,7 & 23,4 & 25,0 & 43,3 & 35,1 & 61,1 \\
\hline & RJ & 83,4 & 3,6 & 24,6 & 5,5 & 25,5 & 47,1 & 24,2 \\
\hline & $S P$ & 88,1 & 7,4 & 40,9 & 9,5 & 17,8 & 49,6 & 40,7 \\
\hline \multirow{3}{*}{ Sul } & PR & 89,0 & 15,8 & 45,1 & 10,0 & 5,4 & 68,3 & 62,1 \\
\hline & SC & 93,3 & 19,4 & 51,8 & 25,2 & 8,9 & 73,8 & 70,7 \\
\hline & RS & 92,4 & 21,0 & 49,9 & 37,9 & 7,2 & 82,4 & 70,2 \\
\hline Brasil & & 83,1 & 8,0 & 20,2 & 21,0 & 9,9 & 54,2 & 33,1 \\
\hline
\end{tabular}

Fonte: IBGE (2020).

Elaboração dos autores.

Entre todos os aspectos listados, chama a atenção o baixo acesso ao crédito por meio de programas de governo, segundo as declarações, sendo que apenas os estados do Sul passaram 
de $15 \%$ dos estabelecimentos que tomaram esse tipo de crédito e, no outro extremo, nas regiōes Norte e Nordeste, esse percentual não chega a 10\% em nenhum estado e apenas $8 \%$ na média Brasil. Conforme revelado em Santana, Santos e Freitas (2019), há divergência sobre esses dados de crédito declarados no censo de 2017 em relação aos valores disponibilizados pelo Banco Central do Brasil, sendo importantes estudos complementares a esse respeito.

Ainda com relação aos dados mostrados na tabela 4, evidencia-se que a região Norte tem sérios problemas de acesso e de não notificação de energia elétrica, uma vez que apenas Rondônia é atendida por mais de 90\%, Tocantins com 86,4\%, enquanto Amazonas tem $52 \%$. São baixos também os índices estaduais do Acre, Roraima, Amapá e Pará, onde a energia alcança menos de $70 \%$ dos estabelecimentos. Surpreende ainda o fato de que estados como São Paulo, Paraná e Rio de Janeiro tenham mais de 10\% de estabelecimentos sem energia e, principalmente, em estados como Bahia e Sergipe esse índice seja superior a $20 \%$. A qualidade e o preço da energia também são fatores essenciais para as agroindústrias rurais e para a irrigação.

A falta de assistência técnica é conhecida no Brasil, indicando, novamente, deficit maior no Norte e Nordeste, embora tenha bons índices apenas no Distrito Federal, onde mais de três quartos dos agricultores declararam ter esse serviço (tabela 4). Já o uso da irrigação, fator determinante da produtividade por área, parece baixo - em torno de $10 \%$ dos estabelecimentos, de acordo com os dados apresentados na tabela 4 -, embora com aumento gradual, principalmente para grãos e cana-de-açúcar (ANA, 2017). É importante, nesse tema, identificar onde ocorre e quais são os efeitos da concentração de outorgas e de vazóes de água para poucos produtores, mesmo nos estados com duas ou mais safras não irrigadas, como os do Centro-Oeste, Sul e Sudeste.

Técnicas de preparo do solo e de controle de pragas com o uso de agrotóxicos são difundidas no Brasil, estando relacionadas ao acesso à assistência técnica, às diferenças pelo tipo de produto e sistemas de produção. Por isso, os índices apresentados na tabela 4 acerca do preparo do solo e da defesa das plantaçôes devem ser analisados com os dados qualitativos locais, que englobem o uso de máquinas, os tipos de produtos e os sistemas de produção. Na mesma linha, o associativismo e o cooperativismo, que se fazem presentes de forma significativa em todas as regióes, devem ser estudados tendo-se em conta os aspectos motivadores e os objetivos dos associados, sendo importante analisar suas iniciativas e efeitos produzidos localmente, bem como a sua relação com a assistência técnica, custos de produção e comercialização.

O difícil acesso à terra, por parte dos agricultores mais pobres, tem sido evidenciado como um dos principais fatores da disparidade de renda no meio rural. Entre os mais de 5 milhóes de estabelecimentos, 93,6\%, ou seja, 4.751 .193 declararam ter tido produção agropecuária; e destes, $80 \%$ (3.796.594) obtiveram receitas da sua produção - outras atividades produtivas (agroturismo, artesanato etc.) foram registradas em mais de $351 \mathrm{mil}$ estabelecimentos (IBGE, 2020). O número de estabelecimentos com produção por estratos de área total que tiveram renda em 2017 (gráfico 1) mostra que há prevalência de unidades de até 200 ha, sendo o tamanho mais comum entre 5 ha e 100 ha. 


\section{GRÁFICO 1}

Quantidade de estabelecimentos agropecuários que obtiveram receitas agropecuárias e outras rendas do produtor por grupos de área total: todas as categorias

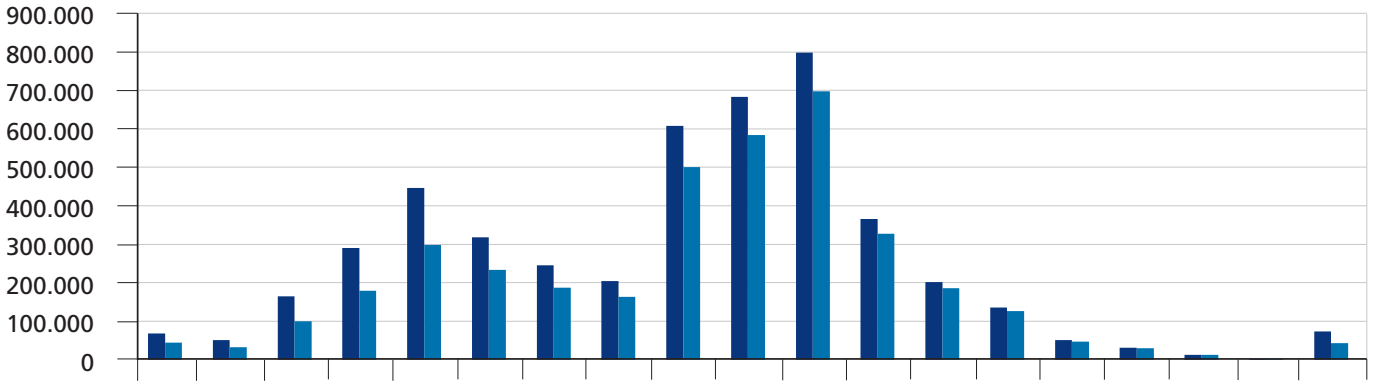

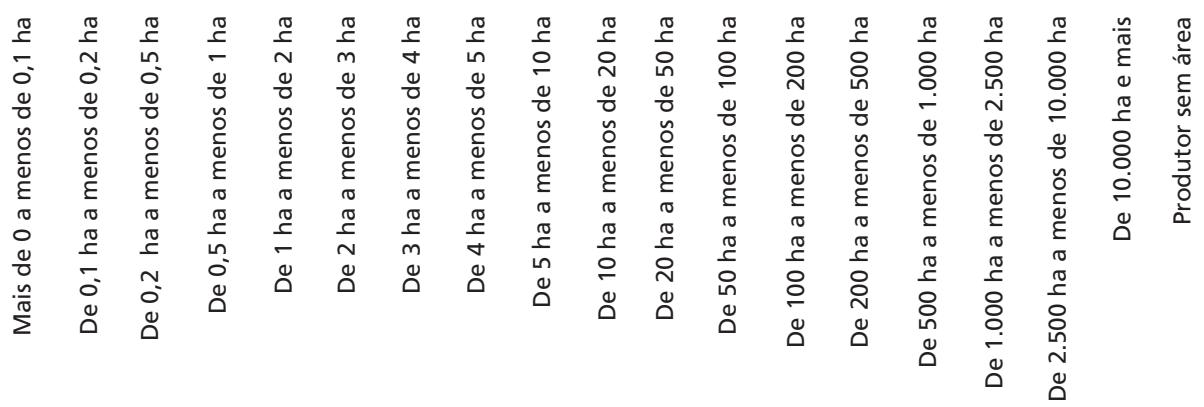

Estabelecimentos com produção

Estabelecimentos com receitas da produção

Fonte: IBGE (2020)

Elaboração dos autores.

A relação direta obtida com os dados do gráfico é que, quanto menor a área, menor é o percentual de estabelecimentos com renda da produção, como de fato se deve esperar. Esse aspecto, somado ao fato de haver mais de 15 milhóes de trabalhadores ocupados no campo, exemplifica as capacidades e o interesse da mão de obra rural. Cabe identificar, em cada realidade regional, as condiçóes nas quais os produtores têm interesse em se reproduzir e qual nível de acesso aos meios de produção é capaz de remunerar os esforços empreendidos.

Considerando-se os estabelecimentos de menor porte, de menor grau de tecnologia, crédito, assistência e demais infraestruturas, o censo de 2017 registrou quase 1,34 milhão de estabelecimentos sem renda da produção agropecuária em 2017. Esse dado aponta o grande peso da produçáo para consumo próprio e outros usos da terra. A figura 1 ressalta regionalmente esse aspecto, sinalizando os municípios onde predominam os estabelecimentos com esse perfil.

De acordo com a figura, a regiáo do Semiárido concentra os municípios com produção para consumo próprio. A regiáo tem grande proporção de minifúndios e passou por uma severa seca entre 2012 e 2017 (Santana e Santos, 2020; Aquino e Nascimento, 2020), realçando dois aspectos da $\mathrm{HE}$ que interessam às políticas públicas: o grande impacto dos ativos físicos (terra e água, neste caso) nos resultados da produção; e, ao mesmo tempo, a grande resiliência dos produtores, que conseguem se manter no campo com baixa renda da produçáo agropecuária, como se detalha, neste boletim, no texto de Joacir Rufino de Aquino, Maria Odete Alves e Maria de Fátima Vidal. 
FIGURA 1

Perfil dos municípios pelo percentual de estabelecimentos com produção para o consumo próprio: todas as categorias

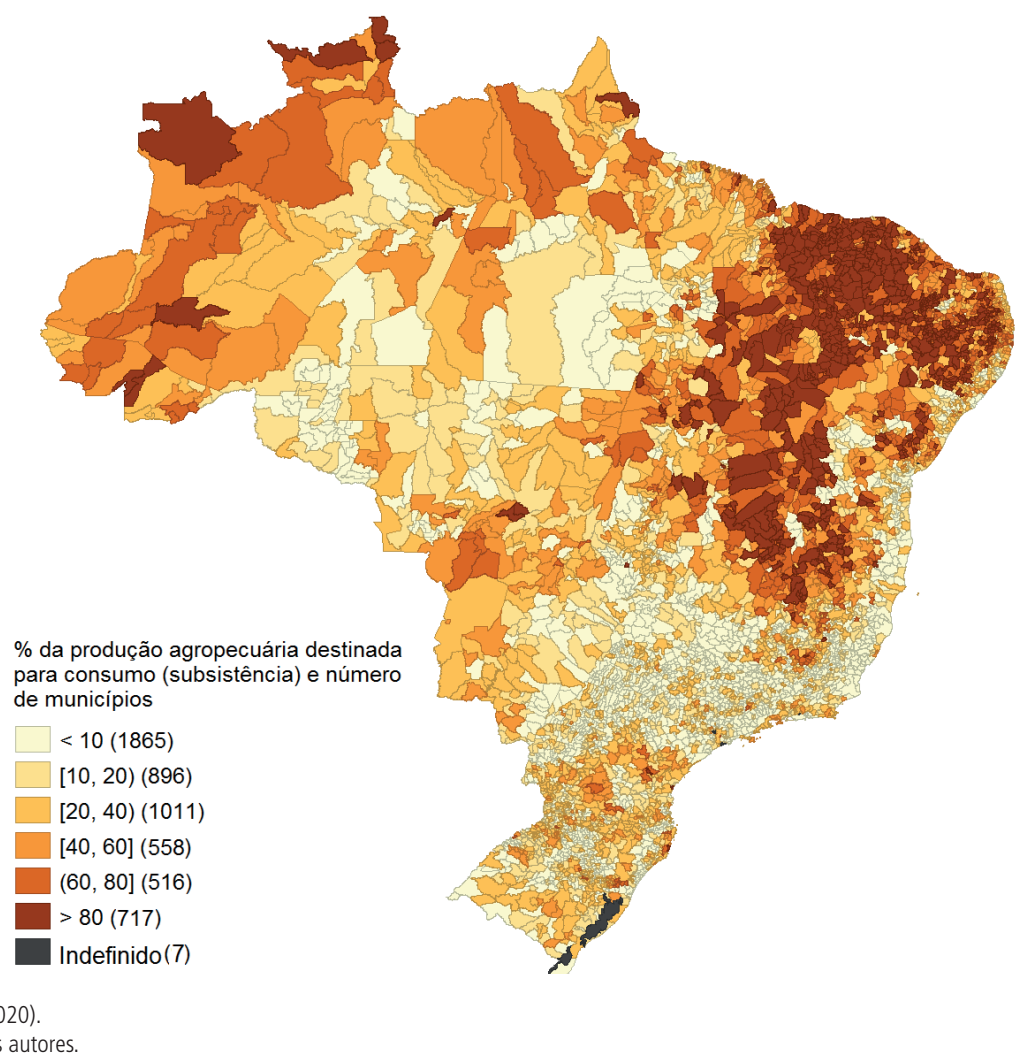

Nesse contexto, destaca-se a grande importância da renda externa aos estabelecimentos ${ }^{9}$ em relaçáo ao total da renda obtida pela soma da receita da produçáo com outras rendas (do estabelecimento e do produtor), principalmente para a agricultura familiar (gráfico 2). Nos estados do Nordeste essas rendas superam $40 \%$ do total da renda dos agricultores familiares, sendo que no Ceará e Piauí superam $60 \%$. Cabe registrar que as receitas externas incluem outros negócios fora da atividade agrícola, não estando necessariamente associada diretamente à pluriatividade dos estabelecimentos, principalmente no caso da agricultura não familiar.

A mencionada resiliência dos produtores da regiáo Nordeste, como também ocorre marcantemente na regiáo Sul e de forma geral na agricultura de pequeno porte em todo o Brasil, é tanto o resultado como a causa da sua multifuncionalidade e pluriatividade. Tais características podem ser explicadas, além do fator renda externa ilustrada no gráfico 2 , pelo apoio de políticas públicas, como evidenciado nos artigos regionais deste boletim. Como tem mostrado o debate acadêmico, a grande capacidade de adaptação e a longa convivência com dificuldades e desafios estruturais e dinâmicos da produção são fatores que devem ser referência para o apoio do Estado aos agricultores, como ocorre em todos os países.

9. 0 leitor poderá obter as rendas externas e internas aos estabelecimentos, por tipo, valores, localidades e atividades, na tabela 6901 do Censo Agropecuário de 2017, disponível em: <https://sidra.ibge.gov.br/tabela/6901>. 
GRÁFICO 2

Participação das outras receitas ${ }^{1}$ em relação ao total de receitas: familiar e não familiar (2017)

(Em \%)

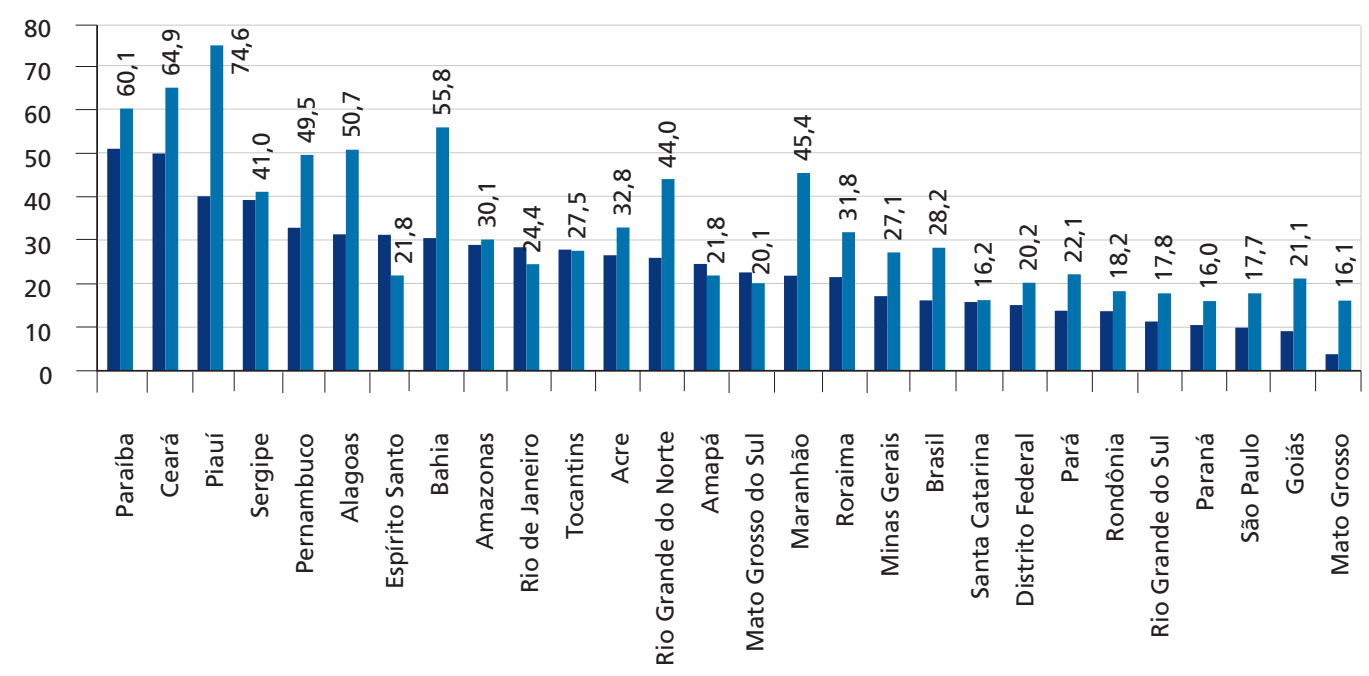

Outras receitas do produtor residente em estabelecimentos com receita (todos os agricultores)/receita total desses estabelecimentos + outras receitas do produtor desses estabelecimentos

- Outras receitas do produtor residente em estabelecimentos com receita (agricultura familiar)/receita total desses estabelecimentos + outras receitas do produtor familiar desses estabelecimentos

Fonte: IBGE (2020)

Elaboração dos autores.

Nota: ' Outras receitas dos estabelecimentos são aquelas oriundas de atividades não agrícolas (como turismo rural), e outras receitas do produtor são aposentadorias, pensões, trabalho externo e outras. A receita total é a soma dessas duas receitas.

\section{CONSIDERAÇÕES FINAIS}

Este texto procurou, dentro dos limites de espaço disponíveis, destacar dados do censo agropecuário que mostram a complexidade do ambiente de atuação da política agrícola e de seus instrumentos, tendo em vista a heterogeneidade da agricultura. Destacaram-se aspectos regionais e de grupos de produtores a partir de variáveis que mostram suas dificuldades e desafios, ilustrando aspectos da pluriatividade e da multifuncionalidade dos estabelecimentos.

Tendo os produtores rurais como principal recorte dessas análises, os estudos sobre a HP podem contribuir ao seguir, resumidamente, cinco recortes básicos inicialmente discutidos neste texto: i) que há 1,36 milhão de propriedades agrícolas em diferentes municípios e regióes com predominância da produção para autoconsumo e outras tantas com baixa produtividade, sendo os motivos distintos e igualmente superáveis de forma coletiva e com políticas adequadas; ii) tendo em vista as políticas públicas estruturantes, os estabelecimentos que produzem apenas para o consumo próprio devem ser foco de estudos a fundo, sempre tendo em conta fenômenos atenuantes como a recente grande seca no Nordeste; iii) além da já citada carência de ativos importantes (como terra, crédito, assistência técnica, componentes de tecnologias), a atenção com a multifuncionalidade e com a pluriatividade deve ser fortalecida nas políticas públicas, de modo a aprimorar as açóes para realidades regionais e rurais, tendo em vista não apenas as características produtivas; iv) a concentração da produção em estabelecimentos da categoria comercial, bem como em apenas sete UFs, deve ser observada tendo-se em conta as privaçóes de acesso a ativos, a baixa eficácia de políticas públicas distributivas, as vantagens de cultivos em larga escala e em mais de uma safra anual e a condição de escassez de água, no caso do Semiárido; e v) as funçôes não agrícolas da terra (como as de casa de campo, ou residência rural de ocupados do meio urbano) e de produção para consumo próprio estão em todas as regióes, e mais claramente no Norte e Nordeste. 
Para os produtores familiares, categoria de maior interesse neste trabalho, verificou-se grande dependência de renda externa aos estabelecimentos. Nesses casos, é fundamental a ampliação do acesso aos ativos físicos, bem como a tecnologias, assistência técnica, capacitação e infraestruturas produtivas. Contudo, há de se compreender que há limites estruturais, ambientais e culturais, além dos organizativos, que levam a náo convergência produtiva, sendo a diversidade inerente ao ambiente de vida e de produçáo rurais. Desse modo, a existência de heterogeneidades deve ser vista como justificativa de aperfeiçoamento das políticas públicas, porém sempre considerando a perspectiva de reconhecer e valorizar a diversidade e sua pluralidade, aspectos marcantes da resiliência das pequenas propriedades nos últimos trinta anos.

\section{REFERÊNCIAS}

ANA - AGÊNCIA NACIONAL DE ÁGUAS. Atlas de irrigação: uso da água na agricultura irrigada. Brasília: ANA, 2017. Disponível em: <http://atlasirrigacao.ana.gov.br/>. Acesso em: 10 mar. 2020.

AQUINO, J. R.; NASCIMENTO, C. A. A grande seca e as fontes de ocupação e renda das famílias rurais no Nordeste do Brasil. Revista Econômica do Nordeste, Fortaleza, v. 51, n. 2, p. 81-97, abr./jun. 2020.

BAIARDI, A.; ALENCAR, C. M. M. Agricultura familiar, seu interesse acadêmico, sua lógica constitutiva e sua resiliência no Brasil. Revista de Economia e Sociologia Rural, Piracicaba, v. 52, p. 45-62, 2014. Supl. 1.

BARBOSA FILHO, F. H.; PESSÔA, S. A. Pessoal ocupado e jornada de trabalho: uma releitura da evolução da produtividade no Brasil. Revista Brasileira de Economia, Rio de Janeiro, v. 68, n. 2, p. 149-169, abr./jun. 2014.

BELIK, W. Agroindústria e política agroindustrial no Brasil. In: RAMOS, P. (Org.). Dimensóes do agronegócio brasileiro. Brasília: Nead, 2007. p. 141-170.

A heterogeneidade e suas implicaçôes para as políticas públicas no rural brasileiro.

Revista de Economia e Sociologia Rural, Piracicaba, v. 53, n. 1, p. 9-30, jan./mar. 2015.

DEL GROSSI, M. E. Algoritmo para delimitação da agricultura familiar no Censo Agropecuário 2017, visando à inclusão de variável no banco de dados do Censo, disponível para ampla consulta. Brasília: FAO, 2019. 25 p. Disponível em: <https://sidra.ibge.gov. br/Content/Documentos/CA/Metodologia\%20Agricultura\%20familiar\%20(IBGE)\%20 DelGrossi\%20final\%205jun2019.pdf>.

FREITAS, R. E.; SANTOS, G. R. Crédito agrícola no Brasil: trajetória recente, desafios e oportunidades. Boletim Regional, Urbano e Ambiental, Brasília: Ipea, n. 17, p. 77-87, jul./dez. 2017.

IBGE - INSTITUTO BRASILEIRO DE GEOGRAFIA E ESTATÍ́STICA. Censo Agropecuário 2017. [s.l.]: IBGE, 2020. Disponível em: <https://sidra.ibge.gov.br/pesquisa/censo-agropecuario/ censo-agropecuario-2017>. Acesso em: 28 mar. 2020.

LIMA, S. K. et al. Desenvolvimento rural. Boletim de Políticas Sociais: Acompanhamento e Análise. Brasília: Ipea, n. 26, 2019.

RAMOS, P. Referencial teórico e analítico sobre a agropecuária brasileira. In: RAMOS, P. (Org.). Dimensóes do agronegócio brasileiro. Brasília: Nead, 2007. p. 18-52. 
SANTANA, A. S.; SANTOS, G. R. Impactos da seca de 2012-2017 na região semiárida do Nordeste: notas sobre a abordagem de dados quantitativos e conclusóes qualitativas. Boletim Regional, Urbano e Ambiental, Brasília: Ipea, n. 22, 2020.

SANTANA, A. S.; SANTOS, G. R.; FREITAS, R. E. Acesso ao crédito agrícola no Brasil: dados preliminares do Censo Agropecuário de 2017. Boletim Regional, Urbano e Ambiental, Brasília: Ipea, n. 20, p. 51-61, jan./jun. 2019.

SANTOS, G. R.; FREITAS, R. E. Gasto público com a agricultura no Brasil: uma abordagem a partir de dados agregados. Boletim Regional, Urbano e Ambiental, Brasília: Ipea, n. 17, p. 89-98, jul./dez. 2017.

SANTOS, G. R.; VIAN, C. E. F.; MATTEI, L. F. Políticas públicas para a agropecuária após a Constituição de 1988: notas conceituais e definições de suporte ao debate. Boletim Regional, Urbano e Ambiental, Brasília: Ipea, 2020.

SCHNEIDER, S. Reflexóes sobre diversidade e diversificação: agricultura, formas familiares e desenvolvimento rural. Ruris: Revista do Centro de Estudos Rurais, Campinas, v. 4, n. 1, p. $85-131,2010$.

SCHNEIDER, S. et al. Pluriatividade e plurirrendimentos nos estabelecimentos agropecuários do Brasil e das regióes Sul e Nordeste: uma análise a partir do Censo Agropecuário 2006. Brasília: Ipea, 2013.

SILVA, S. P. A agricultura familiar e suas múltiplas interaçóes com o território: uma análise de suas características multifuncionais e pluriativas. Rio de Janeiro: Ipea, 2015. (Texto para Discussão, n. 2076).

VIEIRA FILHO, J. E. R.; SANTOS, G. R.; FORNAZIER, A. Distribuiçáo produtiva e tecnológica da agricultura brasileira e sua heterogeneidade estrutural. Brasília: Cepal, 2013. (Texto para Discussão, n. 54). Disponível em: <https://repositorio.cepal.org/bitstream/ handle/11362/36848/1/LCBRSR277_pt.pdf>. 
